\title{
Opportunistic protozoan infections in human immunodeficiency virus disease: Review highlighting diagnostic and therapeutic aspects
}

\author{
A Curry, A J Turner, S Lucas
}

\section{Introduction}

Opportunistic protozoan infections are among the most serious infections in patients with AIDS. ${ }^{1-4}$ They cause severe morbidity and mortality; because many are treatable, it is important that early and accurate diagnoses are made. This is normally accomplished by direct microscopic visualisation of the parasite in infected tissues or body secretions. Rigid adherence to normal diagnostic procedures may not be appropriate in patients with AIDS because the site and manifestation of some of these infections may be unusual. Experience of these conditions among histopathologists and microbiologists is extremely variable. Furthermore, treatment of the protozoan infections in patients with AIDS is often complicated by severe side effects and a high rate of recurrence.

We review the known protozoan infections in human immunodeficiency virus (HIV) seropositive people, the appropriate tissues to sample, the light and electron microscopic appearances, and briefly outline appropriate antibiotic treatment. The protozoa identified to date in these patients are listed in the table.

\section{Predominantly intestinal infections}

Various infectious agents have been found in the gastrointestinal tract of patients with AIDS, ${ }^{5-7}$ some of which may be associated with symptoms. For potential protozoan infections, several stool samples should be examined for cysts or oocysts before invasive procedures are considered. If microscopical examination of wet preparations or fixed and stained stool samples fails to show the presence of an infectious agent, then biopsy may be necessary. A rectal biopsy specimen, which is easily taken, may indicate the presence of a protozoan infection, but it is not always the most appropriate site of the intestine to sample. For some protozoan infections, such as microsporidiosis, diagnosis is impossible without biopsy of the small bowel.

Coccidioses Coccidian protozoa are all intracellular parasites with complex life cycles comprising asexual (schizogony), sexual (gametogony), and sporogenous phases. At some stage in their respective life cycles, all possess characteristic structures, which can be seen under the electron microscope.

Cryptosporidium Now the most well recognised of intestinal coccidia, ${ }^{8-10}$ human Cryptosporidium infection was considered to be both rare and zoonotic before the advent of
AIDS. The AIDS epidemic has considerably increased our awareness of this organism, which is now known to be a common childhood infection among the immunocompetent in whom the infection is self-limiting. ${ }^{8}$ In patients with AIDS and in other immunocompromised groups infection can be both protracted and life threatening. It has a particularly high incidence in HIV positive patients with diarrhoea in Africa ${ }^{11}$ and it is found in up to $10 \%$ of most series of HIV positive patients with diarrhoea in the United Kingdom and the United States of America. The gastrointestinal tract from oesophagus to rectum, the biliary tract including intrahepatic ducts, and the bronchial tree can be infected in patients with AIDS..$^{12}{ }^{13}$ Infection is caused by the ingestion of oocysts in food or water.

Cryotosporidium under both the light microscope and the electron microscope occupies an extracytoplasmic location within an intracellular parasitophagous vacuole (figs 1, 2, and 3). Laboratory diagnosis of Cryptosporidium infection requires the staining of oocysts in faecal smears with modified ZiehlNeelsen or auramine stains. ${ }^{14}$ Monoclonal

\section{Protozoa found in HIV seropositive patients}

$$
\begin{aligned}
& \text { Phylum sporozoa (alt: Apicomplexa) } \\
& \text { Class Coccidea } \\
& \text { Order Eimeriida } \\
& \text { Cryptosporidium } \\
& \text { Isospora } \\
& \text { Sarcocystis } \\
& \text { Toxoplasma } \\
& \text { Class Piroplasmea } \\
& \text { Order Piroplasmida } \\
& \text { Babesia } \\
& \text { Class Haemosporidea } \\
& \text { Order Haemosporida } \\
& \text { Plasmodium } \\
& \text { Phylum Microsporidia (alt: Microspora) } \\
& \text { Class Microsporea } \\
& \text { Order Microsporidia } \\
& \text { Encephalitozoon } \\
& \text { Enterocytozoon } \\
& \text { Phylum Rhizopoda } \\
& \text { Class Lobosea } \\
& \text { Entamoeba } \\
& \text { Acanthamoeba } \\
& \text { Phylum Metamonada } \\
& \text { Class Anaxostylea } \\
& \text { Order Diplomonadida } \\
& \text { Giardia } \\
& \text { Phylum Kinetoplasta } \\
& \text { Order Trypanosomatida } \\
& \text { Trypanosoma } \\
& \text { Leishmania }
\end{aligned}
$$

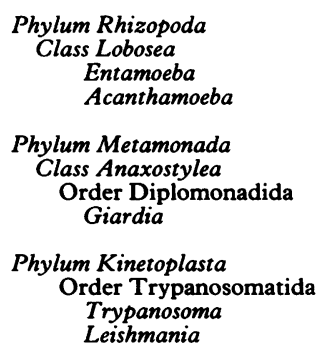

Phylum Kinetoplasta Order Trypanosomatida

Possible protozoon: Blastocystis

Protozoon or fungus: Pneumocystis
Correspondence to: Dr A Curry

Accepted for publication 26 July 1990 
Figure 1

Cryptosporidium in a rectal biopsy specimen. Note the superficial

location of this parasite

(haematoxylin and eosin).

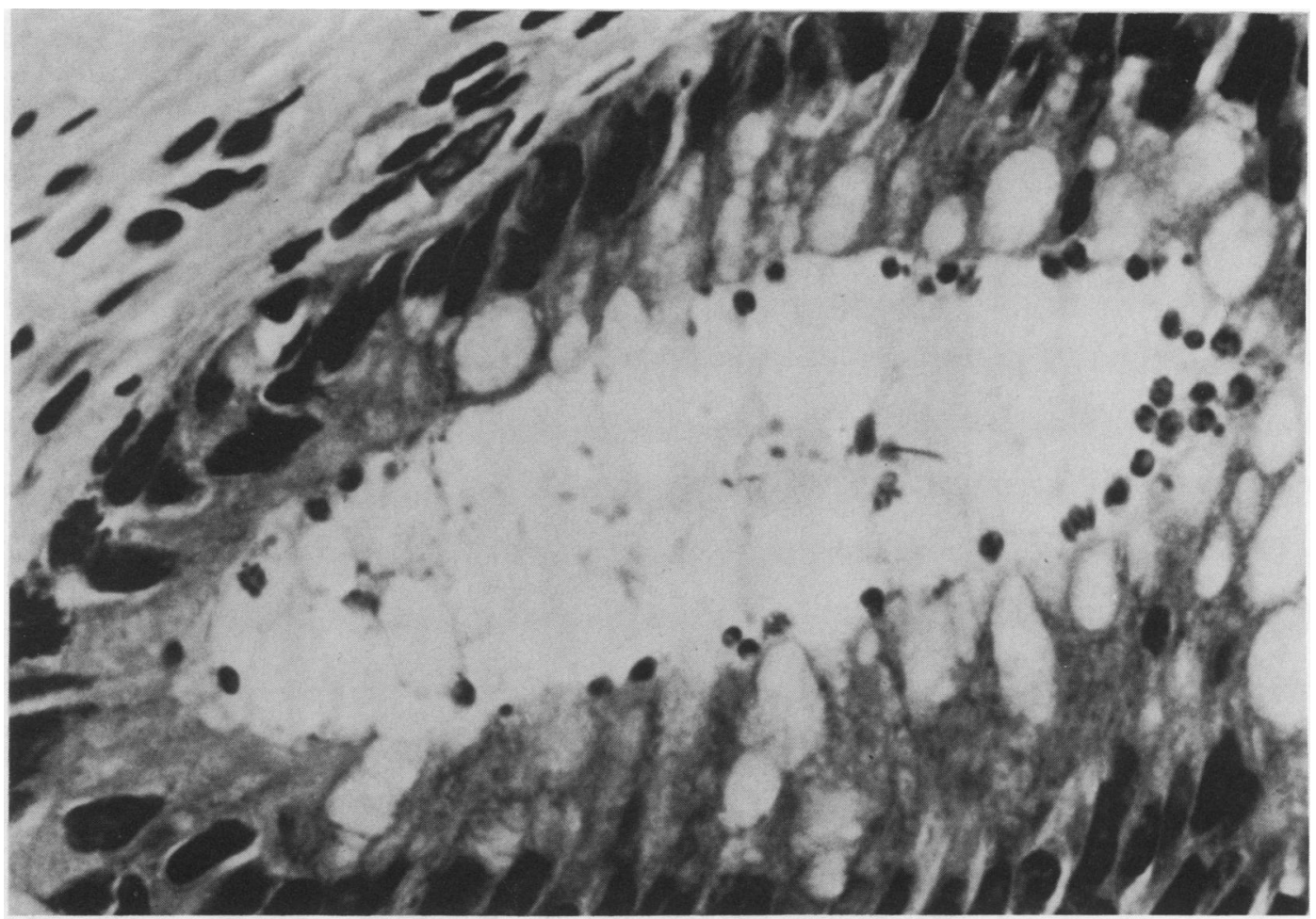

antibodies have been used on faecal smears and paraffin wax sections, but they stain only oocysts and not the smaller trophozoites. ${ }^{15} \mathrm{~A}$ rectal biopsy specimen shows the parasite in many cases, but a duodenal biopsy specimen is probably more sensitive; both tissue biopsy specimens and faecal smears can identify a small proportion of organisms that the other modality has missed. ${ }^{16}$

Attempts to treat Cryptosoporidium infection have met with limited success. Most reports concern the use of spiramycin ${ }^{17}$; relapses are common, occurring in up to $50 \%$ of patients at three months. Although a large number of other drugs have been used, there is no established effective treatment.

Isospora Before the advent of AIDS there were few recorded human intestinal infections caused by Isospora belli. ${ }^{5}$ In some countries or

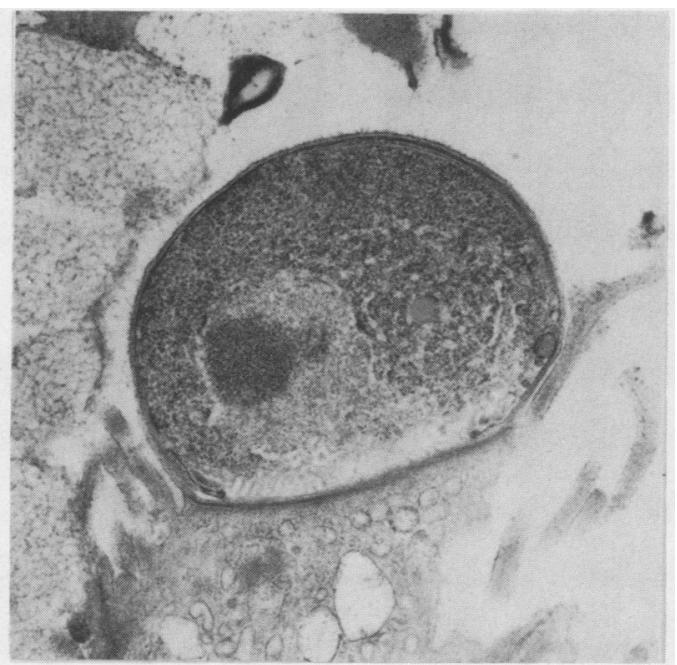

Figure 2 Electron micrograph of a human rectal biopsy specimen showing intracellular but extracytoplasmic location of a late trophozoite stage of Cryptosporidium. in ethnic groups within countries, however, isosporiasis is relatively common in patients with AIDS. ${ }^{18}$ In the United States of America $8 \%$; the incidence among others with AIDS is $1 \% .{ }^{19}$ A similar high incidence of $I$ belli has been noted in Haitian patients with AIDS $(12 \%)$ and in Africa. ${ }^{11} 161820$ This organism has also been recorded in patients with AIDS in the United Kingdom (S Lucas, personal observations). The zoonotic reservoir-if there is one-is unknown.

Chronic watery diarrhoea is the major symptom of isosporiasis. Infection is presumably through ingestion of oocysts in food or water. The infected enterocytes of the small intestine (the main organ infected) show completely intracellular and intracytoplasmic parasites (figs 4-7). There is some evidence for

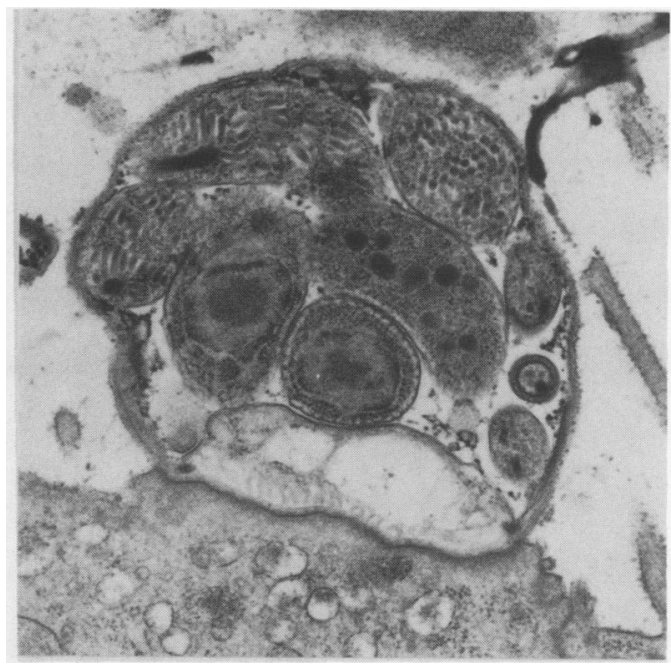

Figure 3 Electron micrograph of a schizont of Cryptosporidium. the incidence among Hispanics with AIDS is 


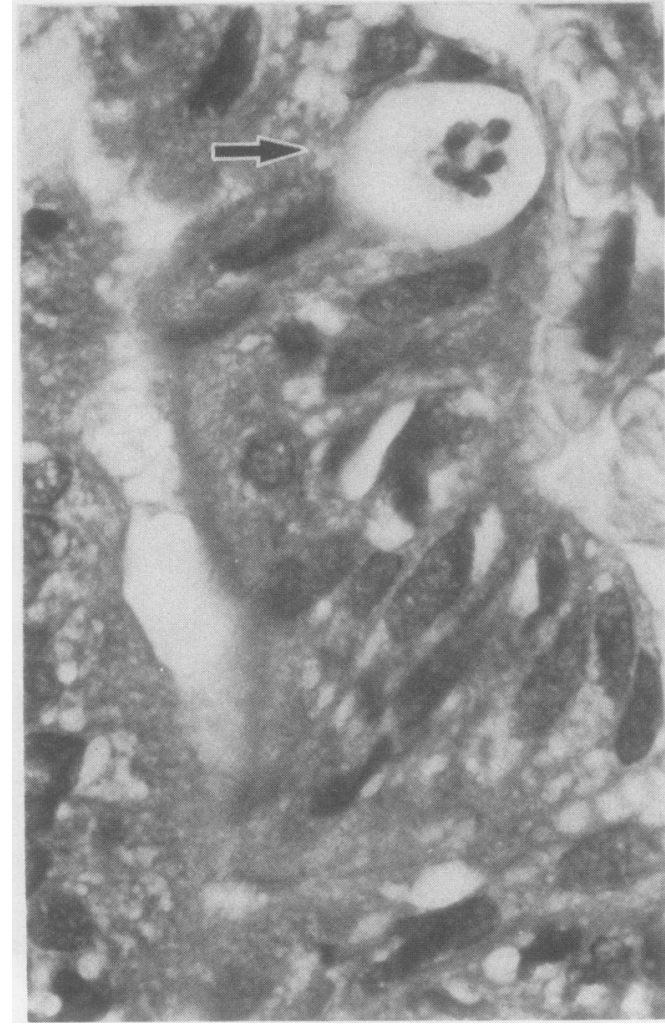

Figure 4 Four zoites of Isospora seen in cross section (arrowhead) within a duodenal enterocyte (haematoxylin and eosin).

latency, as isosporiasis may develop several months or years after presumed exposure. ${ }^{19}$ Mild to severe mucosal inflammation, often with eosinophilia, and crypt hyperplastic atrophy occur; the parasites vary in abundance. Extraintestinal infection by Isospora has been described in a patient with AIDS in whom both the small and large bowel were infected; the organism was also found in mesenteric lymph nodes. ${ }^{21}$

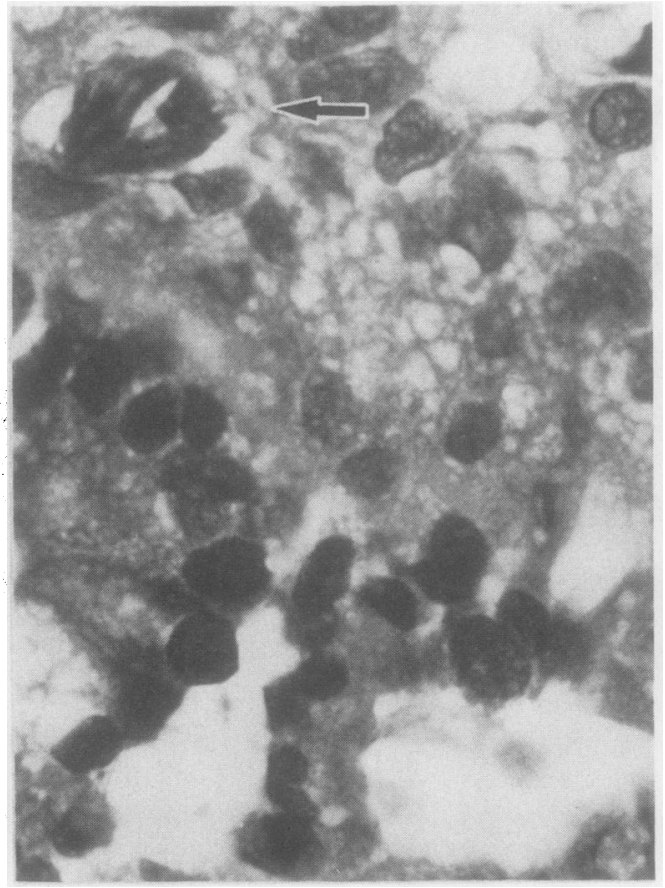

Figure 5 Six sickle-shaped zoites of Isospora seen in longitudinal section in a duodenal biopsy specimen (arrowhead) (haematoxylin and eosin).

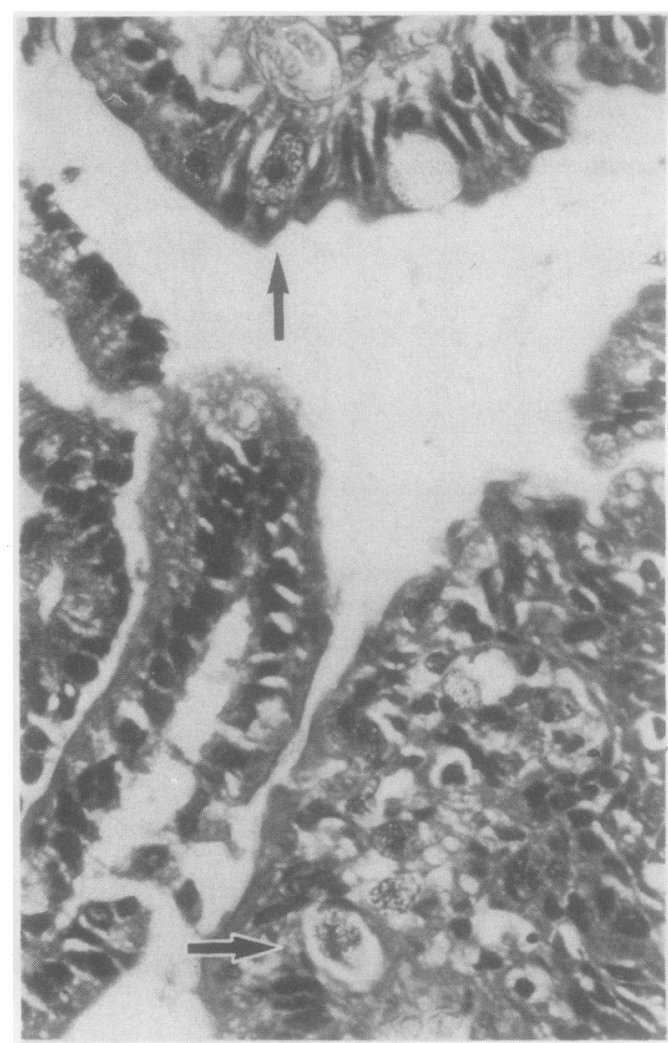

Figure 6 Early schizonts of Isospora-large granular mononuclear cells arrowed (haematoxylin and eosin).

Laboratory diagnosis of Isospora depends on faecal examination for oocysts (fig 8) or a biopsy of the small intestine where the enteric stages may be found in the gut wall. Competent histological diagnosis is complicated by the similarity of this organism to both Sarcocystis and Toxoplasma; it is larger than microsporidia. Like Cryptosporidium, tissue biopsy specimens and faecal smears identify small numbers of cases the other modality has

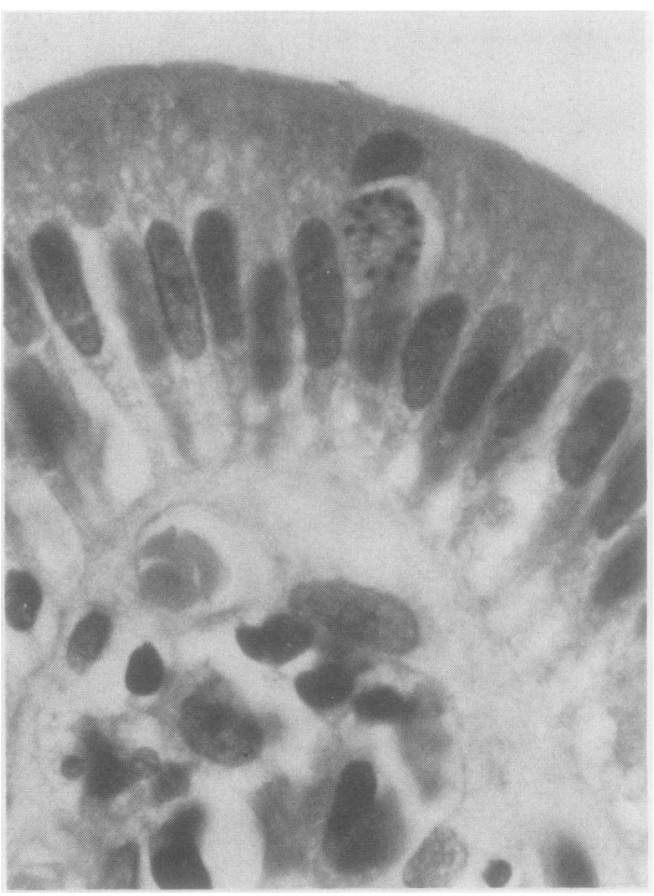

Figure 7 Multinucleated gametocyte of Isospora in an enterocyte (haematoxylin and eosin). 
Figure 8 Faecal smear with four ovoid oocysts of Isospora belli (modified Ziehl-Neelsen).

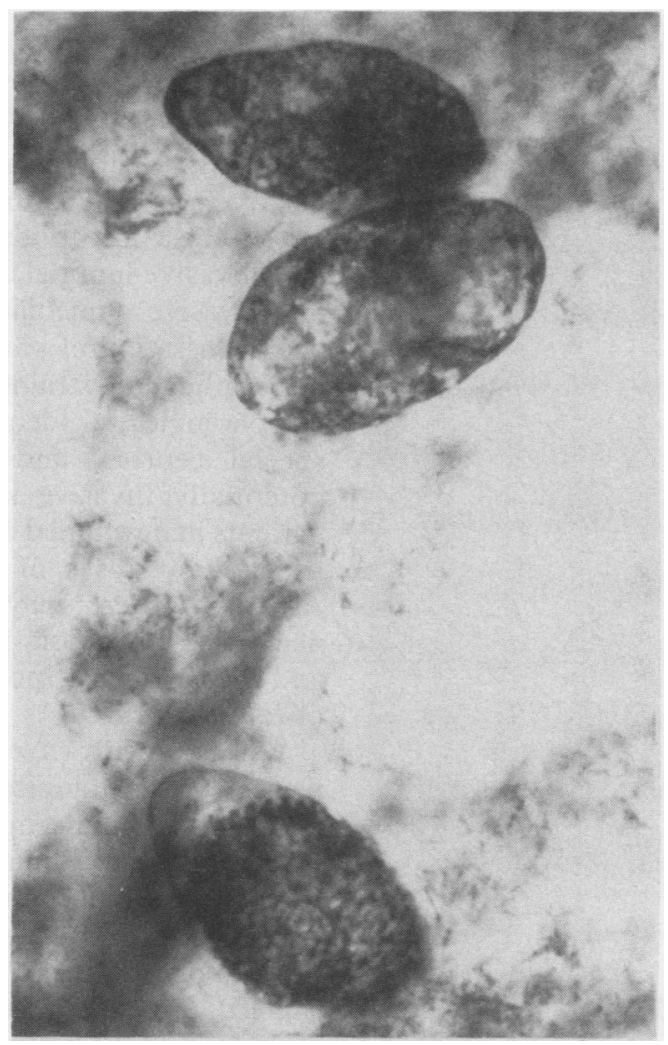

missed, but faecal smears are more sensitive. ${ }^{16}$

In some reports patients with isosporiasis have responded well to co-trimoxazole, although recurrence is common (about $50 \%$ ). Prophylaxis with co-trimoxazole or pyrimethamine-sulphadoxine prevents recurrence for up to 16 months, with a low rate of adverse reactions. ${ }^{22}$ In a Zambian study, however, patients with diarrhoea associated with isosporiasis did not improve on co-trimoxazole. ${ }^{16}$ Sarcocystis Sarcocystis hominis and $S$ suihominis intestinal infections are rare. A recent report in an HIV infected person ${ }^{23}$ and the case illustrated here were attributed to Sarcocystis (fig 9). Infection is probably exclusively zoonotic in nature. Consumption of poorly cooked, infected muscle releases zoites which infect the enterocytes; the sexual phase of the life cycle then takes place, causing diarrhoea. Oocysts are excreted in faeces (fig 10) and these are similar to those of Isospora, although they have more delicate walls and are more spherical.

\section{Other enteric protozoa}

MICROSPORIDIOSIS

Microsporidia (or microsporans) are a widespread group of obligate intracellular parasitic protozoans, characterised by the possession of a coiled filament seen by electron microscopy within the small resistant spores. ${ }^{24}$ Once the spores have been ingested, this filament uncoils and injects the infective sporoplasm directly into the host enterocytes, where proliferation occurs. Recorded cases of human infection remain uncommon, but this group of organisms is now assuming some prominence in the spectrum of opportunistic infections found in patients with AIDS. Enterocytozoon bieneusi, which was first described in such a patient, ${ }^{25} 26$ seems to be the commonest human microsporidian infection. This organism has only been found in symptomatic patients (up to $6.5 \%)^{27}$ in whom the major features are malabsorption and diarrhoea. Its role in the pathogenesis of diarrhoea is still being debated. It seems to replicate and produce spores exclusively within the small intestinal wall without evoking any major tissue response. A duodenal or jejunal (not rectal) biopsy specimen is therefore necessary for diagnosis. Demonstration of the organisms within small intestinal enterocytes is possible using simple histological strains ${ }^{27}$ (figs 11 and 12), but electron microscopical examination is required for definitive diagnosis, and is more sensitive (figs 13 and 14). ${ }^{28}$ Faecal smear examination is not useful because the small size of the spores $(1 \times$ $1.7 \mu \mathrm{m})$ and the ability of the walls to retain Gram stain make them indistinguishable from Gram positive coccal bacteria. Tissue dabs from small bowel biopsy specimens, however, can be stained with Giemsa to demonstrate microsporans. ${ }^{29}$

Encephalitozoon cuniculi has been reported in a patient with AIDS with peritonitis ${ }^{30}$ and in another with hepatitis. ${ }^{31}$ Several patients in the United States of America have developed conjunctival lesions (keratitis) caused by this organism. Perforation may occur. There is little inflammation; swabs or biopsy specimens of conjunctiva show Giemsa and Gram positive 1-2 $\mu \mathrm{m}$ ovoid organisms, and electron microscopical examination confirms the diagnosis. ${ }^{32} 33$

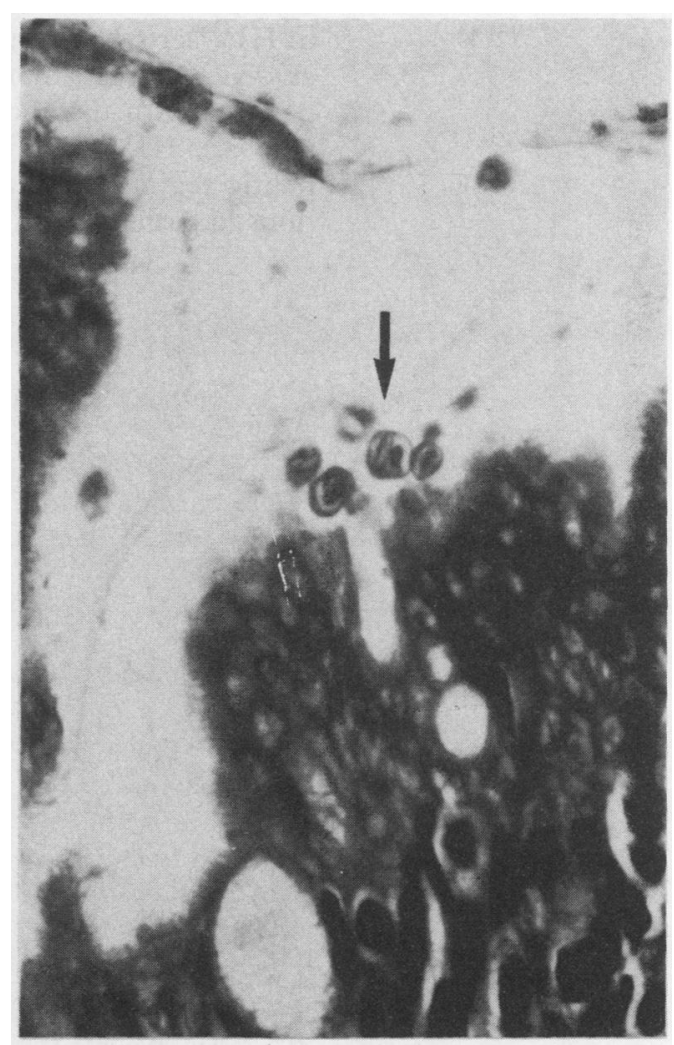

Figure 9 Duodenal biopsy specimen: oocysts of Sarcocystis adjacent to enterocytes (arrowhead) (haematoxylin and eosin). 
Figure 10 Faecal smear of Sarcocystis, showing oocysts as both colourless refractile spheres with internal granular zooites, and as acid-fast sphere (arrowhead) (modified Ziehl-Neelsen).

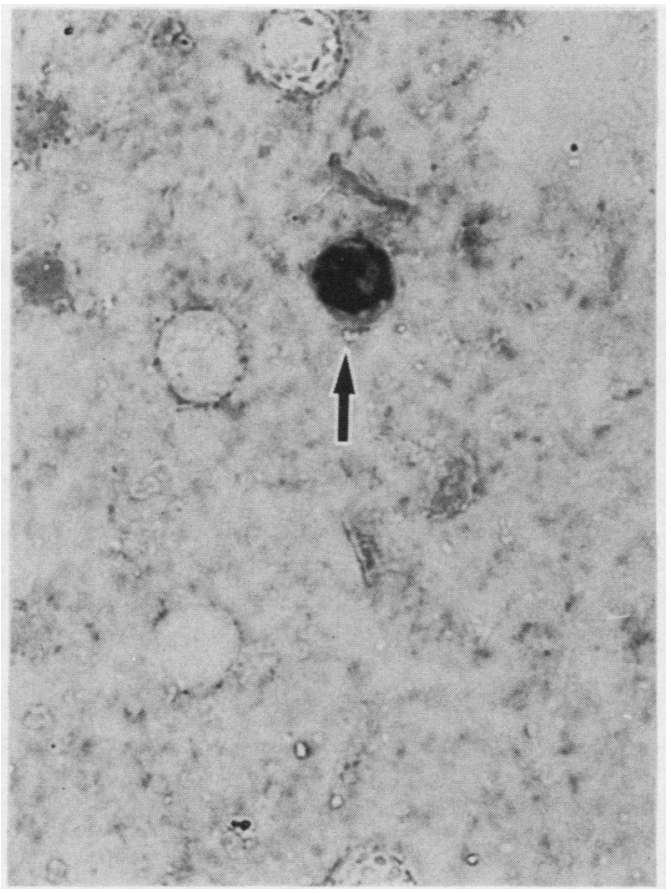

There is no established treatment for microsporidian infection in any site. ${ }^{26}$ In a recent report of five cases of ocular microsporidiosis various topical antibiotics were used with no obvious benefit. ${ }^{33}$

\section{GIARDIASIS}

Giardia lamblia is a flagellate protozoon spread by the faecal-oral route, with a high incidence in homosexual men. ${ }^{3}$ Enteric infection is often asymptomatic. The infection is found globally in HIV seropositive people; so far, there is no evidence that it is more or less common in such patients with diarrhoea compared with those who are HIV negative. Conventional therapeutic regimens are adequate for these infections in patients with AIDS. ${ }^{34}$

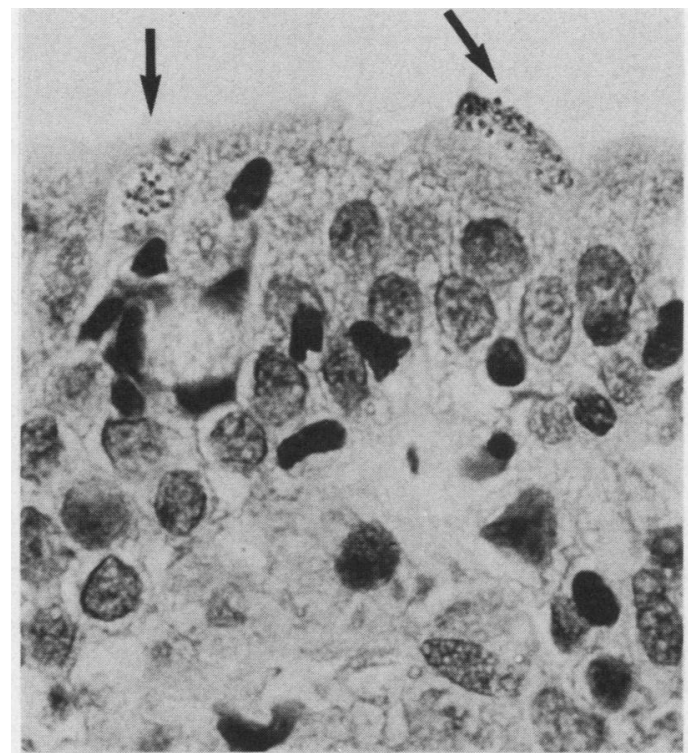

Figure 11 Duodenal biopsy specimen: two enterocytes (arrowheads) contain spores of Enterocytozoon, seen as small refractile haematoxophylic dots (haematoxylin and eosin).

\section{AMOEBIASIS}

Intestinal infection with Entamoeba histolytica may be found in $20 \%$ of homosexual men, irrespective of gastrointestinal tract symptoms, and similar prevalences are seen in HIV positive homosexual men with diarrhoea. ${ }^{35}$ So far, all these infections have taken the form of non-invasive luminal carriage of amoebae, and not invasive amoebiasis proper. ${ }^{36}$ Isoenzyme characterisation of pathogenic compared with non-pathogenic strains of $E$ histolytica that are morphologically identical may be done in special centres, and confirms the lack of potentially invasive strains in HIV positive patients in developed countries. ${ }^{36}$ In fact, given the lack of cases of invasive amoebiasis in Africa, ${ }^{1120}$ there may even be a significant negative association between HIV infection and the carriage of potentially invasive strains of $E$ histolytica. ${ }^{37}$

When non-invasive infections are found in faeces, parasitological examination shows typical cysts and trophozoites, but the latter rarely contain phagocytosed red cells. Similarly, in biopsy material trophozoites may be abundant, but they are not seen to invade mucosa or have red cells within the cytoplasm (fig 15). Amoebic serology, which is sensitive and specific for invasive amoebiasis, is negative in these patients. Conventional therapeutic regimens are adequate for Entamoeba infections in patients with AIDS. ${ }^{34}$

Blastocystis hominis Blastocystis is an amoeboid organism of uncertain taxonomy which seems to have protozoan features (fig 16). ${ }^{38}$ Its role in enteric disease is just as controversial, with some workers convinced of its pathogenic role. ${ }^{39}$ It does not invade tissue, and has not been confidently noted in rectal biopsy specimens.

Beneficial effects have been claimed for treated Blastocystis infection; drugs used include metronidazole, $2 \mathrm{~g}$ daily for two weeks, ${ }^{40}$ and co-trimoxazole, ${ }^{39}$ but the evidence so far is limited.

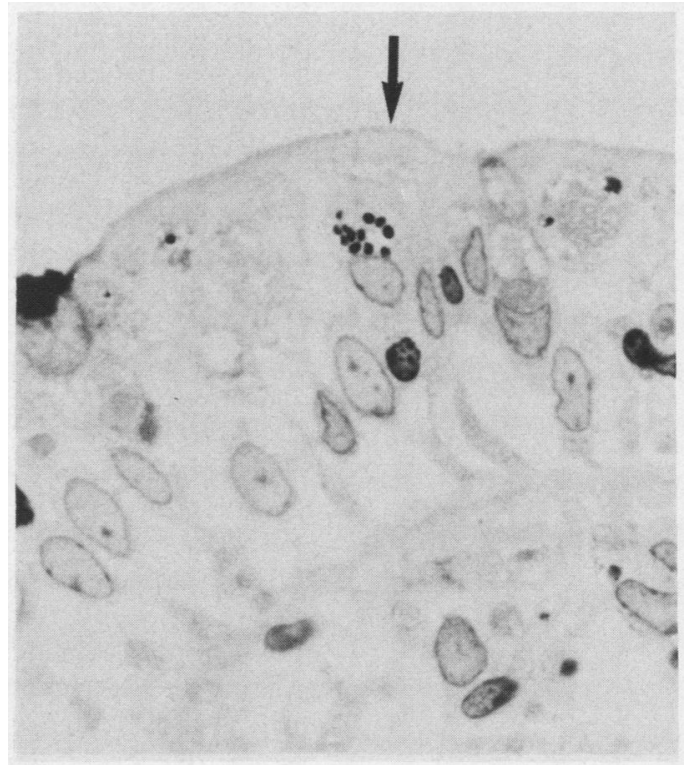

Figure 12 Enterocytozoon spores in duodenal enterocyte (arrowhead); Semithin (Giemsa). 
Figure 13 Electron micrograph of a spore of Enterocytozoon bieneusi in human small intestinal biopsy specimen. Note profiles of internal coiled filament, characteristic of this group of intracellular parasites.
Figure 14 Electron micrograph of an early sporont of Enterocytozoon bieneusi indenting enterocyte nucleus. Note random profiles of spore filaments.

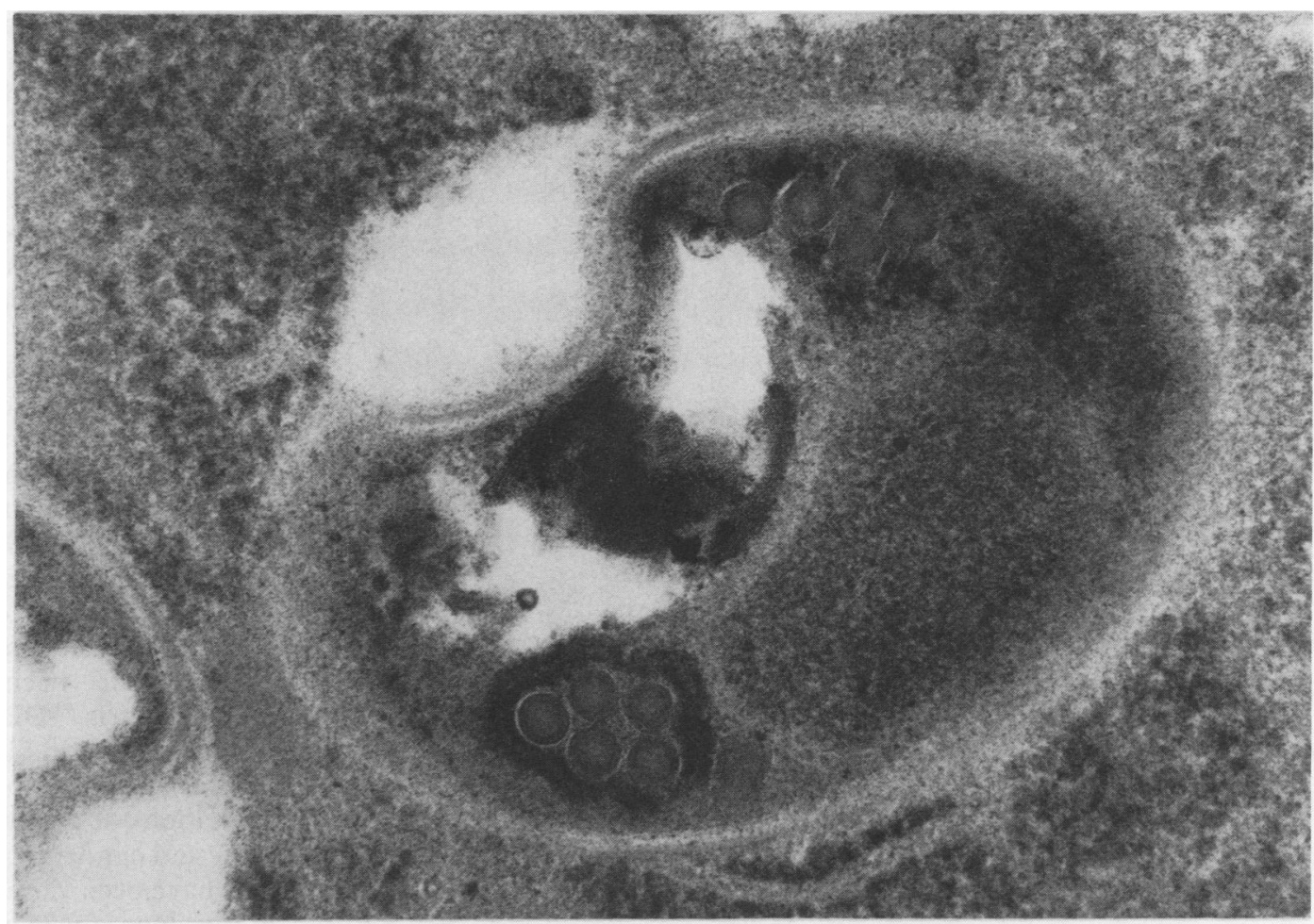

\section{Predominantly extra-intestinal infections TOXOPLASMOSIS}

The coccidian Toxoplasma gondii is a common infection which is not usually pathogenic in immunocompetent hosts. In developed countries $50-90 \%$ of adults are seropositive for Toxoplasma antibodies. The life cycle begins in cats in which the sexual reproductive phase occurs, and continues in man (or other mammals). Ingestion of the infective oocysts containing sporozoites by humans initiates the asexual cycle. The sporozoites are taken up by macrophages in which they rapidly multiply and are carried to various organs. Rupture of the macrophages releases the tachyzoites which disseminate the infection. Ultimately the organisms become enclosed in dormant (latent) tissue cysts in brain and muscle. Clinically important disease in man is largely restricted to congenital infection, generalised lymphadenopathy in primary infection, and reactivated infections in the immunocompromised including HIV positive patients. ${ }^{41}$ The most important manifestation in HIV infected patients is encephalitis, often necrotising and

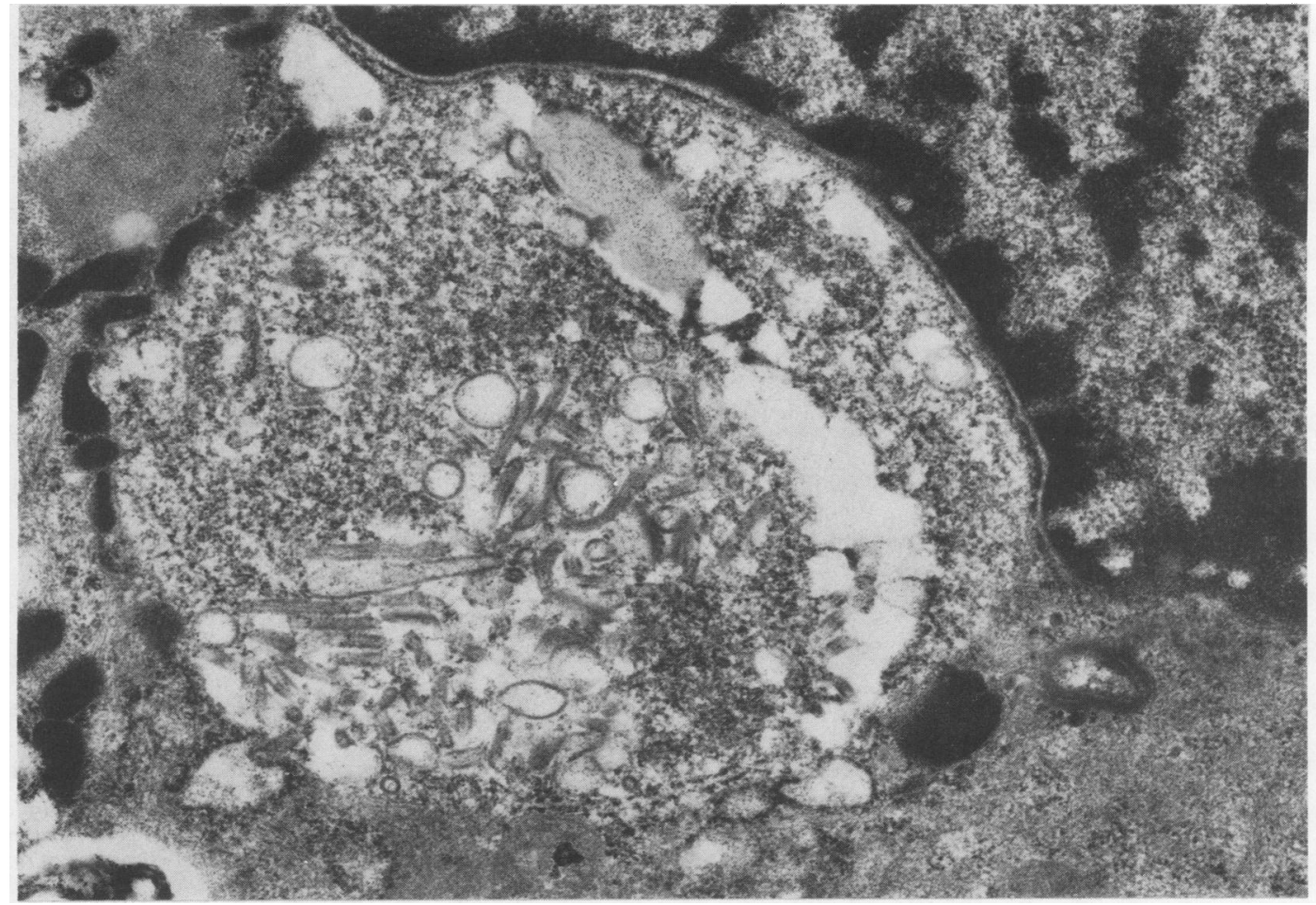




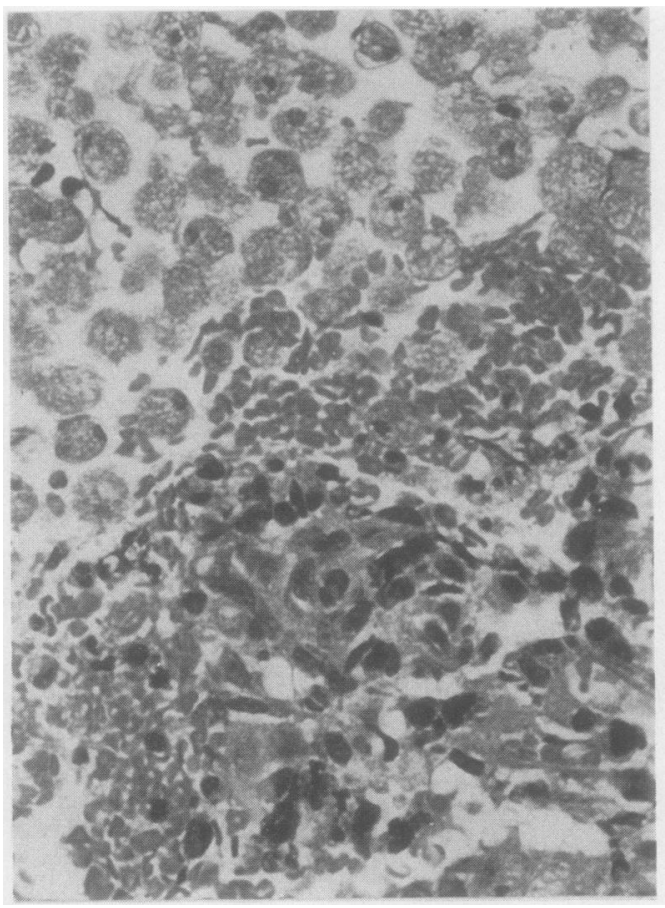

Figure 15 Rectal biopsy specimen: abundant trophozoites of non-pathogenic Entamoeba histolytica adjacent to mucosa. The amoebae have not phagocytosed erythrocytes (haematoxylin and eosin).

often fatal. ${ }^{42}$ Toxoplasma myocarditis, pneumonitis, enteritis and peritonitis are also seen. ${ }^{4344}$ The incidence of active Toxoplasma infection in patients with AIDS can be as high as $70 \%$ in some areas.

Laboratory diagnosis of toxoplasmosis is normally accomplished by serological testing, but such procedures are unreliable ${ }^{14}$ when dealing with patients with AIDS because of varying antibody titres. Histological analysis of tissue (figs 17 and 18) or smears can provide the most dependable diagnosis and this may require immunohistochemical techniques (fig 19) to identify positively the parasite. The use of such invasive procedures is controversial, and if Toxoplasma encephalitis is suspected on

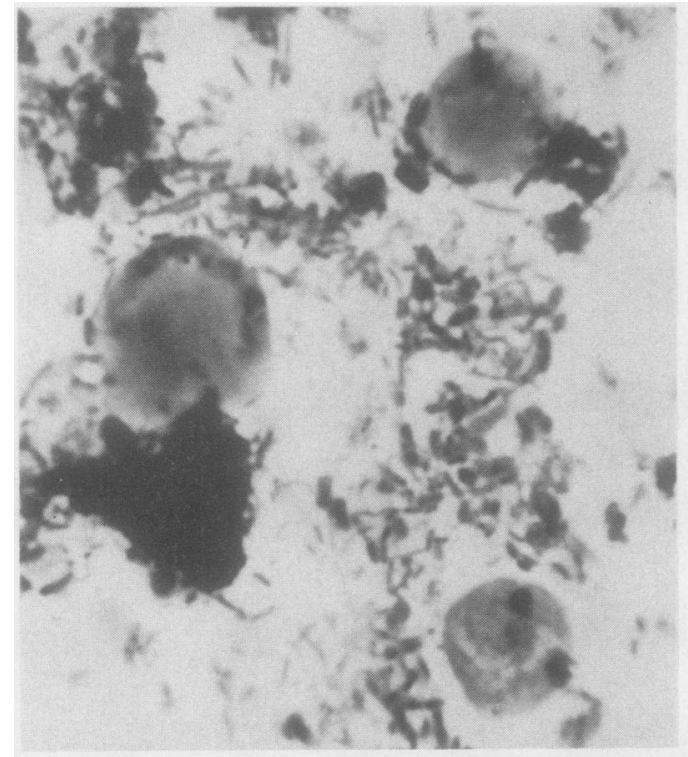

Figure 16 Three Blastocystis organisms in a faecal smear, with surrounding bacteria (Giemsa). clinical grounds anti-toxoplasma treatment is often started without a definitive diagnosis.

The treatment of toxoplasmosis in patients with AIDS has been reviewed recently. ${ }^{45} 46$ Pyrimethamine plus a sulphonamide is the treatment of choice. A high rate of relapse has led to recommendations that prolonged treatment is used, but the role of prophylaxis for all patients with AIDS and serological evidence of Toxoplasma infection is not yet established. ${ }^{45}$

Babesia and Plasmodium species are sporozoan parasites which develop in erythrocytes in their mammalian hosts and in the tick and mosquito vectors, respectively. In man, babesiosis is uncommon, but has now been reported in patients with AIDS in the United States of America. ${ }^{47}$ The disease is associated with fever, anaemia, and splenomegaly. In asplenic patients the parasitaemia may reach $40 \%$ of red cells, and the haemolysis can result in haemoglobinuria. ${ }^{48}$ Diagnosis is made by identifying organisms in blood films. Treatment of Babesia infections in patients with AIDS with combinations of pentamidine, co-trimoxazole, quinine and clindamycin has been tried but the results have been variable and relapses occur.

Plasmodium falciparum malaria occurs in HIV infected people in endemic zones, but the incidence and clinical manifestations seem to be no different from those in HIV negative patients. ${ }^{3749} 50$

Acanthamoeba Like Naegleria, Acanthamoeba is a genus of free-living amoebae. Two cases of acanthamoebiasis have been documented in HIV positive patients. One had focal cerebral signs and numerous foci of haemorrhagic necrosis in cerebrum and cerebellum at necropsy. ${ }^{51}$ The trophozoites are seen in large numbers around necrotic vessels (fig 20), and there may be granulomatous inflammation. The

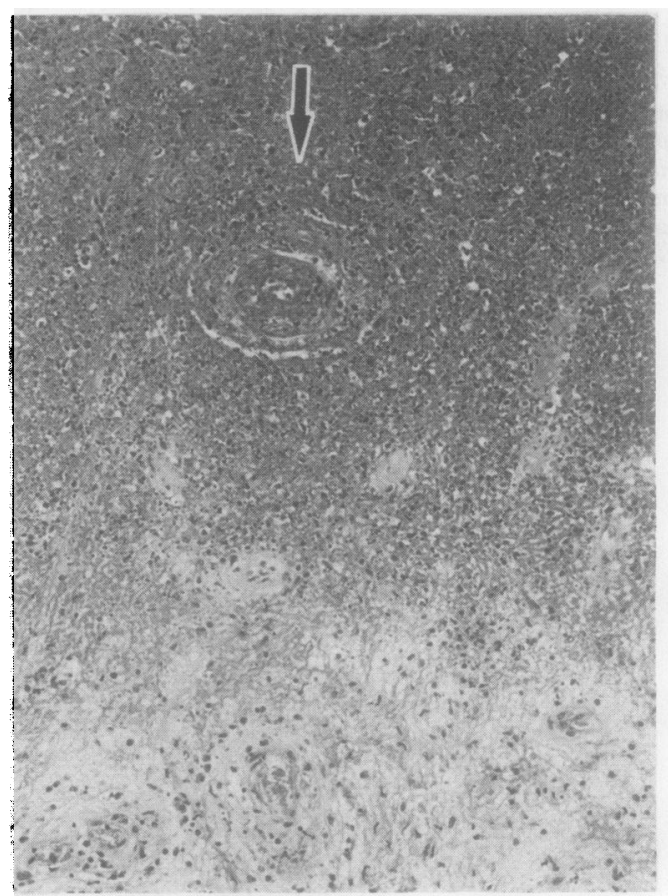

Figure 17 Cerebral toxoplasmic necrosis: the endarteritis and perivascular onion-skinning (arrowhead) is typical of toxoplasmosis (haematoxylin and eosin). 


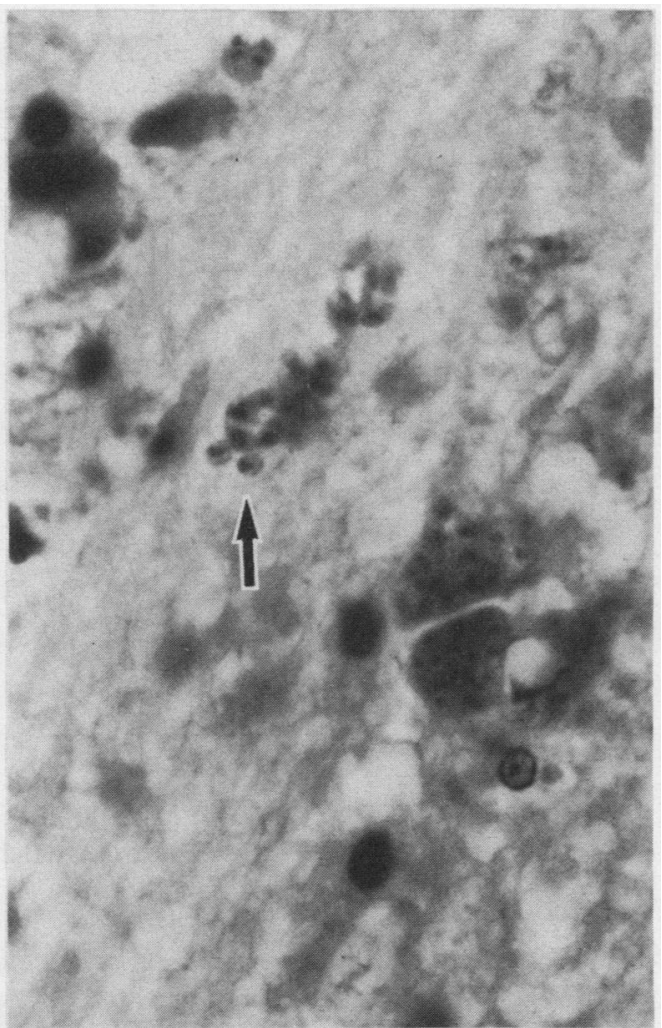

Figure 18 Brain toxoplasmosis: two cysts and a cluster of loose tachyzoites (arrowhead) (haematoxylin and eosin).

other case had Acanthamoeba infection of the paranasal sinus and the dermis of the leg. ${ }^{52}$ The trophozoites are $20-40 \mu \mathrm{m}$ across and possess a prominent nucleolus. Although morphological distinction from Naegleria (which has not yet been reported in HIV positive patients) and Entamoeba is possible, confirmation via specific immunostaining or culture in reference laboratories is recommended. Usually Acanthamoeba encephalitis is diagnosed at necropsy; but diagnosis through examination of cerebrospinal fluid and biopsy specimens is possible. Amphotericin and flucytosine have been recommended for treatment. ${ }^{51}$

The route of infection for Acanthamoeba is uncertain, but it probably requires a skin inoculation or nasal lesion before haematogenous dissemination to brain occurs.

Leishmania is a kinetoplastid flagellate protozoan, which characteristically possesses a DNA-rich organelle associated with the flagellar base called a kinetoplast. Most leishmanial infections in man are zoonotic, the life cycle involving sandflies (the vector) and canines or rodents (the reservoir), depending on the Leishmania species. In man the parasite is seen as the amastigote form (LeishmanDonovan or LD body). Infection is often asymptomatic in endemic areas. Clinicopathologically, there are four main forms of leishmaniasis: visceral (kala azar); cutaneous; muco-cutaneous; and diffuse cutaneous. To date, only the first two patterns have been reported in HIV positive patients, and all these patients have been infected with Leishmania infantum, the common cause of both cutaneous and visceral leishmaniasis in Europe. ${ }^{2}$
Cutaneous leishmaniasis generally heals with activation of macrophages, necrosis, and parasite elimination. A patient with AIDS and a single heavily parasitised leishmanial skin ulcer was reported from Italy; the lesion healed with standard antimonial chemotherapy, and at no time was there evidence of visceralisation. ${ }^{53}$ In regions of Italy where only the dermatotropic strain of $L$ infantum is prevalent, however, HIV infection can be associated with visceral disease alone. ${ }^{54}$

Mucosal leishmaniasis affecting the palate and pharynx has been seen in immunocompromised patients, including those who are HIV positive (S Lucas, personal observations). The pathology is granulomatous with many LD bodies. These lesions are probably extensions from facial infections.

Over 100 cases of visceral leishmaniasis have now been reported in HIV positive patients, all of whom have travelled to, or lived in, the Mediterranean countries of France, Spain, Portugal, Italy and Malta. ${ }^{55}$ Patients may present with typical hepatosplenomegaly, anaemia, and fever. Parasites can usually be shown by aspiration of spleen, marrow, lymph nodes or skin. Histologically, they are usually evident in a tissue biopsy specimen such as liver and marrow; Kupffer cells and macrophages contain abundant LD bodies, and there is associated plasmacytosis (fig 21).

Unusual lesions are also found. A skin biopsy specimen for diagnosing Kaposi's sarcoma may show LD bodies in dermal macrophages amid the tumour lesion before there is clinical suspicion of visceral leishmaniasis (fig 22). ${ }^{56}$

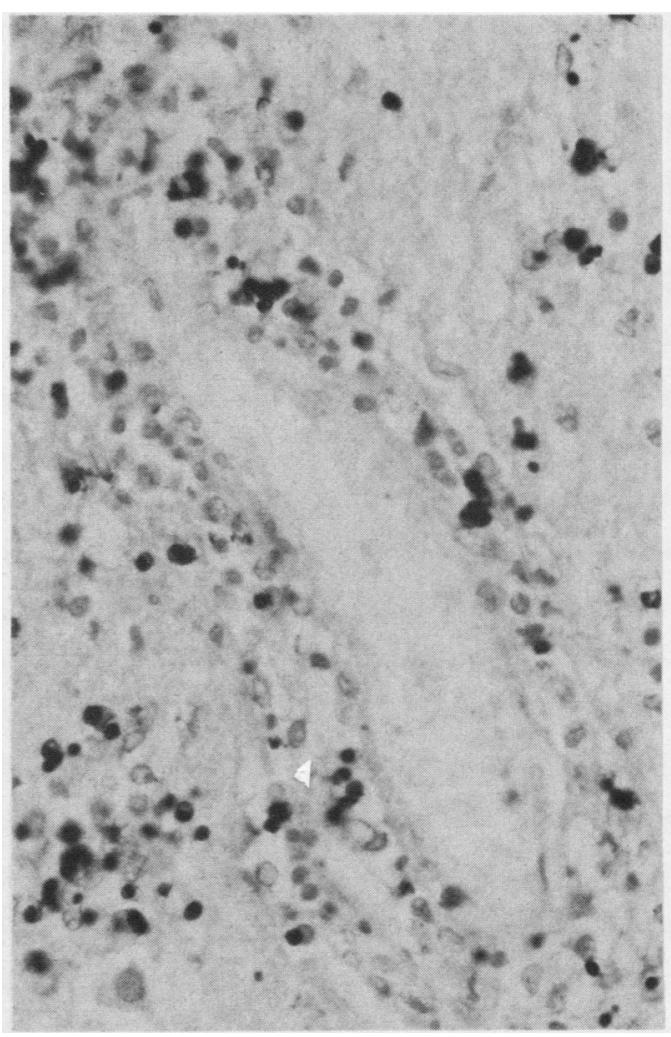

Figure 19 Immunostaining with Bioquote monoclonal anti-toxoplasma antibody showing numerous zoites, with many in the vessel wall (immunoperoxidase). 
Figure 20 Brain biopsy specimen from patient with AIDS with

Acanthamoeba encephalitis. Large trophozoites with central nucleolus seen clustered together and around $a$ blood vessel (haematoxylin and eosin).

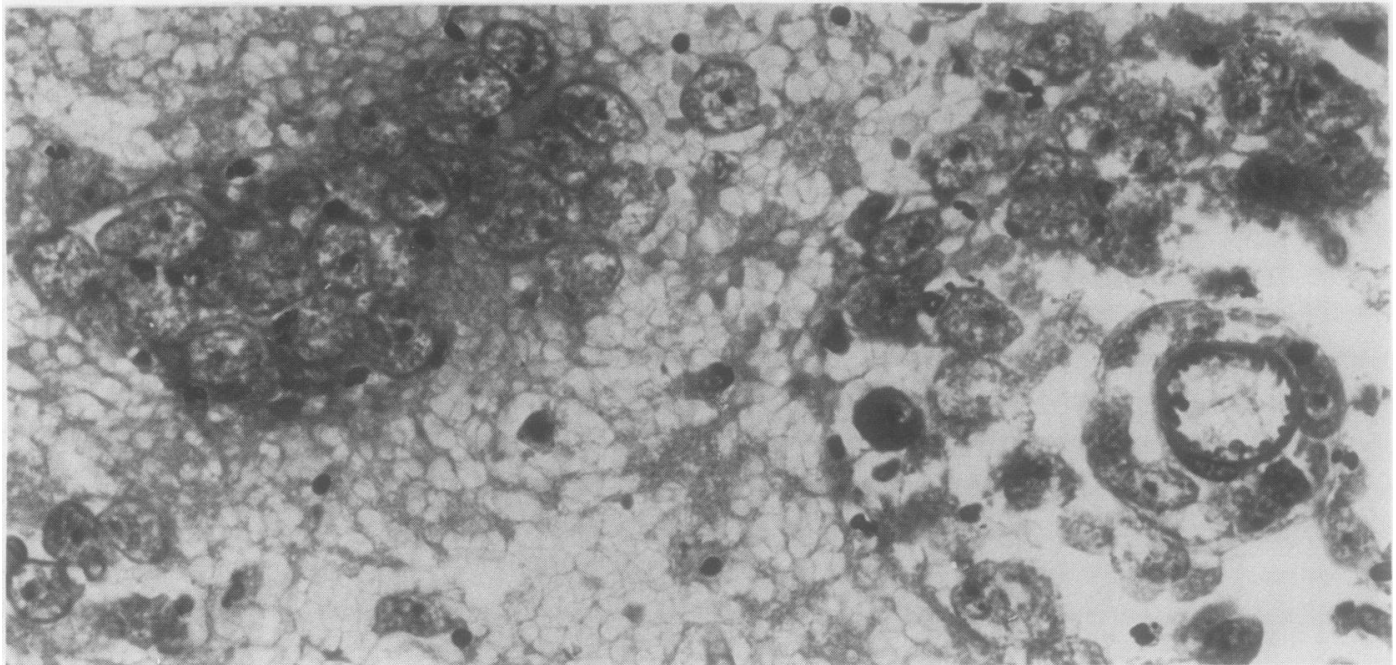

Intestinal tumour-like lesions composed of abundant leishmanial bodies in macrophages ${ }^{57}$ and incidental observation of parasitised rectal lamina propria are also features (fig 23). In visceral leishmaniasis without HIV infection parasitism of alveolar macrophages has occasionally been seen, but in a case of pleural effusion in an HIV positive man, LD bodies were identified in macrophages from a pleural tap. ${ }^{58}$

Visceral leishmaniasis may be diagnosed by serology, but it is not always seropositive in HIV positive patients. ${ }^{59}$ Chemotherapy clears the parasite from most patients, but the relapse rate is high. Treatment for visceral leishmaniasis has been reviewed in detail elsewhere. ${ }^{55}$ Although a number of drugs have been used, ${ }^{60}$ the antimonial sodium stibogluconate (Pentostam) remains the treatment of choice.

Trypanosoma Like Leishmania, trypanosomes are kinetoplastid flagellates. They inhabit the bloodstream and other tissues of vertebrates, including man; the insect vectors are Tsetse flies (African) and Reduviid bugs (South American). African trypanosomiasis (sleeping sickness) is caused by Trypanosoma brucei. This infection does not seem to be more prevalent in HIV positive people or more severe compared with the normal population in Africa. ${ }^{61}$

In South America $T$ cruzi infection causes Chagas' disease. Seroepidemiological studies in Brasil have found evidence of trypanosomal infection among HIV positive people but without a significant association. ${ }^{61}$ A cerebral abscess caused by $T$ cruzi in an HIV positive patient has been reported (Kronfeld A, Sprintz E, Cavacanti A, Carneiro A. Abstract presented at Fifth International Conference on AIDS, Montreal, June 1990). Histologically, the amastigotes of $T$ cruzi resemble toxoplasmas; they possess a kinetoplast (like Leishmania); immunostaining for toxoplasmosis on sections is specific.

Treatment for trypanosomiasis has been reviewed in detail recently elsewhere. ${ }^{55}$ The two drugs of confirmed efficacy for South American trypanosomiasis are nifurtimox and benznidazole.
Pneumocystis carinii Pneumocystis is an enigmatic micro-organism of uncertain taxonomy. It has been shunted backwards and forwards between the fungi and the protozoa. Recently ribosomal RNA homology studies $^{62}$ have shown identical nucleic acid sequences with some fungi, but some mycologists remain to be convinced that this is where this organism belongs. $^{63}$ The organism seems to be ubiquitous, infecting man and other mammals in many parts of the world. It leads an extracellular existence within the alveolar lung spaces. $^{64}$ Two distinct forms are apparent within the alveoli, a pleomorphic form (trophozoite) with a full complement of eukaryotic organelles (including an enveloped nucleus and mitochondria), and a spherical thick-walled cystic stage, often enclosing several intracystic bodies with a similar appearance to the trophozoite. The wall of the trophozoite compr-

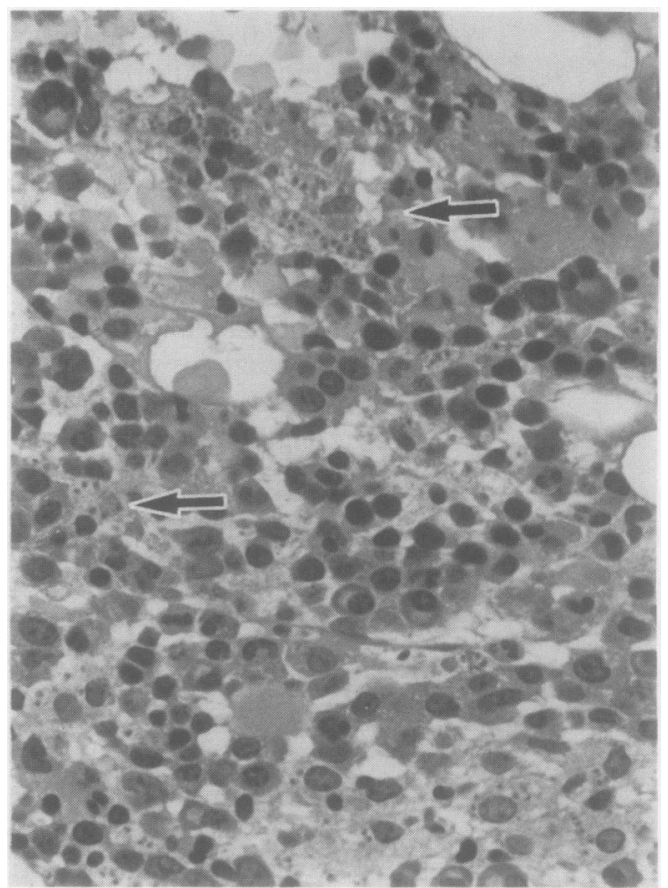

Figure 21 Bone marrow with visceral leishmaniasis. Arrowhead indicates $L D$ bodies (Methacrylate embedded; haematozylin and eosin). 
Figure 22 Skinbiopsy specimen from a Kaposi's sarcoma plaque: numerous $L D$ bodies in macrophages between the vascular slits (haematoxylin and eosin). Slide by courtesy of $\operatorname{Dr} R$ Lindley, St Stephen's Hospital.

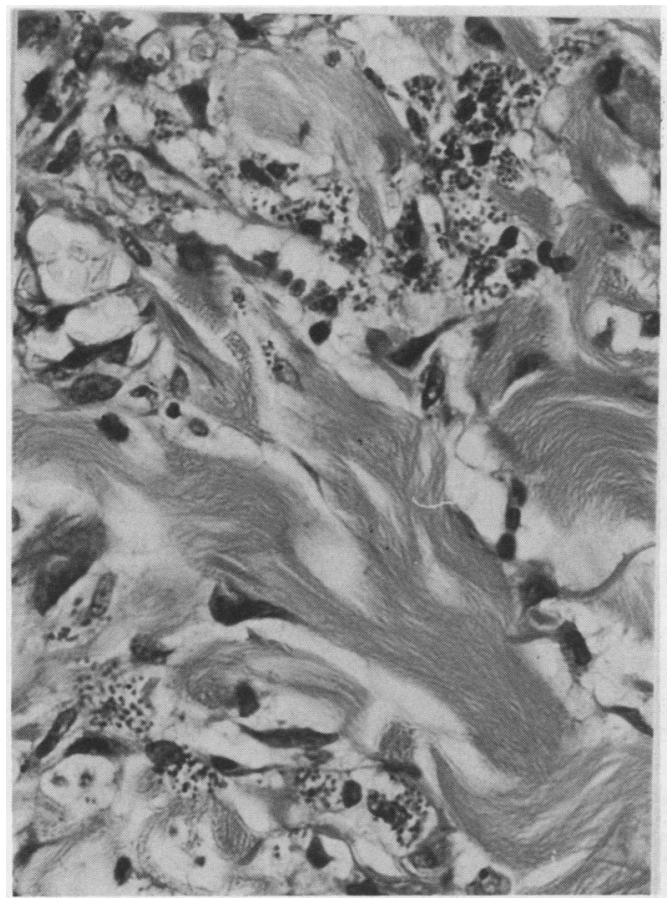

ises a single unit membrane covered by an external thin electron dense covering.

Asymptomatic infection in childhood is common, with up to two thirds of normal children of four years of age having antibody to Pneumocystis. ${ }^{65}$ The route of infection is presumably airborne. The most critical factor in the pathogenesis of Pneumocystis carinii pneumonia (PCP) in HIV positive patients is the circulating $\mathrm{CD} 4$ lymphocyte count, an indicator of the degree of immunocompetence. It has been shown that until the $\mathrm{CD} 4$ count drops below $200 / \mathrm{mm}^{3}$, PCP is rare. ${ }^{1}$

The occurrence of a cluster of cases of PCP was one of the first manifestations of the AIDS epidemic and PCP has remained the initial presentation of AIDS in $60 \%$ of patients in North America, ultimately occurring in at least $85 \%$ of patients. ${ }^{66}$ It is fatal in $5-10 \%$ of initial episodes; recurrences almost always occur. For second or subsequent episodes, the average survival is about $60 \%$. ${ }^{67}$

Although most Pneumocystis infection in patients with AIDS remains pulmonary, this organism is occasionally found in non-pulmonary sites ${ }^{689}$ such as the ear, ${ }^{7071}$ liver (fig 24), spleen, small intestine, ${ }^{72}$ lymph nodes, skin, ${ }^{7374}$ pancreas, kidney, urethra, adrenals, thyroid, mesentery, heart, ${ }^{75}$ choroid, ${ }^{6976}$ bone marrow ${ }^{77}$ and the Virchow-Robin spaces of the brain. ${ }^{78}$ Some, but not all, of this extrapulmonary invasion is associated with the use of nebulised pentamidine. ${ }^{79}$ The organism perhaps invades tissues which contain a much lower concentration of pentamidine. Extrapulmonary Pneumocystis, however, has also been found in the absence of any clinical pulmonary disease. ${ }^{72}$

The macroscopic appearances of PCP are well known-a pale dry pneumonic consolidation. Less common is cavitating PCP, where a granulomatous response is found around necrotic areas of lung, and cysts are often more scanty. PCP is in the differential diagnosis of a cavitating pneumonia and may mimic tuberculosis. The cysts also infiltrate under the endothelium of arteries and veins and cause occlusion. ${ }^{80}$ This probably contributes to the pathogenesis of lung cavities; a similar process may have led to necrosis of digits in widely disseminated $P$ carinii infection. ${ }^{74}$ In large deposits of extrapulmonary pneumocystosis, such as in lymph nodes and liver, the gross appearance is of yellowish necrotic deposits. The cysts lie extracellularly, are often degenerate, and only a small proportion take up the methanamine silver stain.

Early in the AIDS epidemic Pneumocystis carinii pneumonia was diagnosed by direct visualisation of the parasite in open lung biopsy or needle biopsy specimens. The complications of such procedures, particularly pneumothorax, meant they were replaced by bronchiolar lavage. Recently, induced sputum has been advocated as a suitable diagnostic specimen. This procedure is certainly less traumatic than either of the original methods but examination of sputum may be a less sensitive technique in patients receiving prophylactic pentamidine. ${ }^{81}$ However specimens are taken, stains such as Giemsa and methanamine silver are used to identify the organism, particularly the cystic stage. More recently, immunocytochemical techniques have been introduced $^{82}$ which are easier to examine and interpret. Sputum and lavage specimens, however, are classified as hazardous, requiring special handling facilities because infectious HIV virus or Mycobacterium tuberculosis may be present in samples before inactivation. Formalin fixation of the sputum or lavage overcomes this problem, but not all commer-

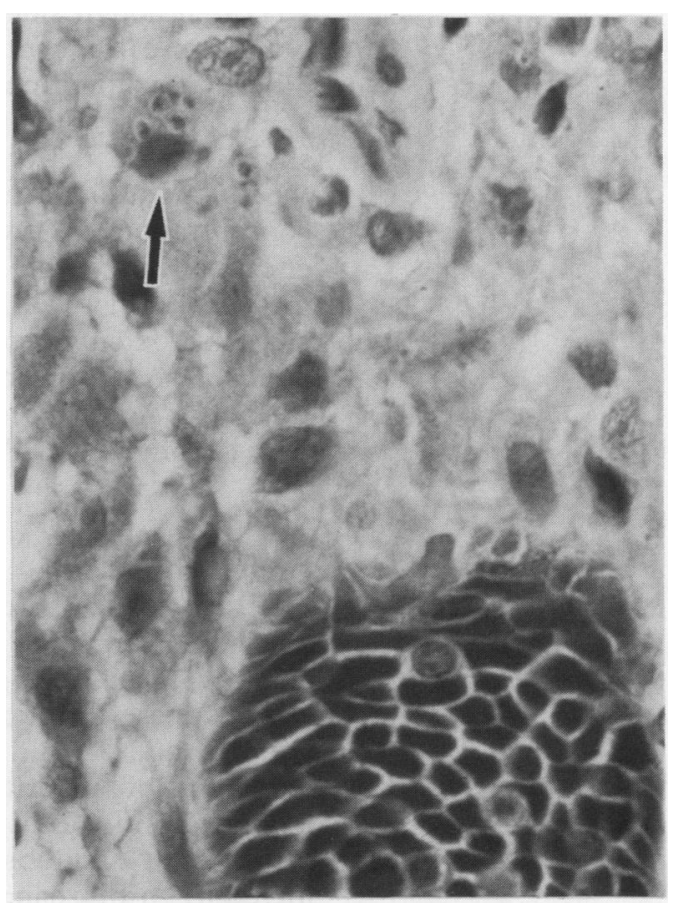

Figure 23 Rectal biopsy specimen from HIV positive seropositive haemophiliac. LD bodies (arrowhead) in lamina propria macrophages (haematoxylin and eosin). (Slide by courtesy of Dr A Vincenti, Winchester). 
Figure 24 Liver biopsy specimen taken after death showing clusters of extracellular Pneumocystis cysts adjacent to hepatocytes (haematoxylin and eosin). (Slide courtesy of Dr R Goldin, St Mary's Hospital).

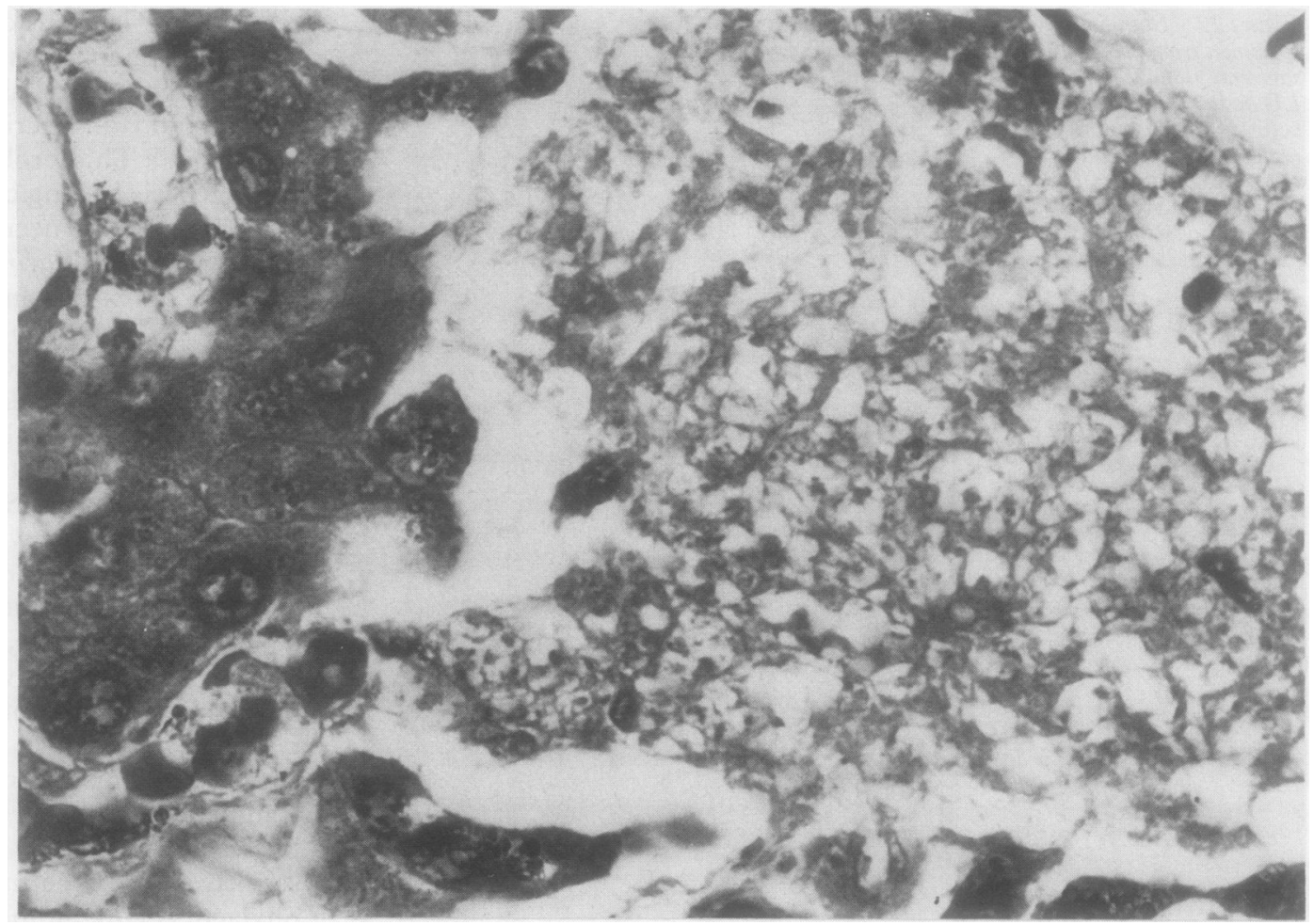

cially available Pneumocystis antibodies are raised to fixed material. In addition, attention has been drawn to the problem of false positive indirect immunofluorescence results, possibly caused by Candida cells becoming opsonised with anti-Candida antibodies and crossreacting with fluorescein isothiocyanate antimouse antibodies in the sputum specimen. ${ }^{83}$

Extensive clinical experience has shown that co-trimoxazole and parenteral pentamidine are effective drugs for treating PCP in patients with AIDS, although side effects are common and occur more frequently than in patients with other types of immune deficiency. ${ }^{67}$

Treatment with aerosolised pentamidine should permit delivery of high drug doses to the lungs without achieving sufficient systemic concentrations to cause toxicity ${ }^{84}$ It may be effective when the pneumonia is mild or moderate, and is well tolerated. Pulmonary and systemic toxicity, extrapulmonary disease, and recurrence, however, all occur. ${ }^{661}$ Aerosol treatment is now used for primary and secondary prophylaxis of PCP.

\section{Conclusions}

HIV infection is here to stay and will spread, albeit with arguable rapidity. If they do not already, histopathologists and microbiologists will diagnose infections among HIV positive patients and should be aware of the wide spectrum of parasitic protozoa potentially involved, and the usual and unusual sites of infection. Undoubtedly, new infections, including protozoanones, are waiting to be described.

We acknowledge the assistance of Drs E Dunbar, DM Jones, LJ McWilliam, and NY Haboubi.
1 Masur H, Ognibene FP, Yarchoan R, et al. CD4 counts as predictors of opportunistic pneumonias in HIV infection. Ann Intern Med 1989;111:223-31.

2 Lucas SB. Aspects of infectious disease. In: Anthony PP MacSween RNM, eds. Recent advances in histopathology. Vol 14. Edinburgh: Churchill Livingstone, 1989:281-302.

3 Cook GC. Opportunistic parasitic infections associated with the acquired immune deficiency syndrome (AIDS) parasitology, clinical presentation, diagnosis and management. $Q J$ Med 1987;65:967-83.

4 Harawi SJ. The microorganisms. Harawi SJ, O'Hara CJ, eds. Pathology and pathophysiology of AIDS and HIV related diseases. London: Chapman and Hall, 1989.57-81.

5 Brandborg LL, Stanley SB, Breidenbach WC. Human coccidiosis- possible cause of malabsortion. The life cocidiosis a possible cause of malabsorption. The life cycle in smant-bowel mucosal biopsies as a diagnostic

6 Warhurst DC, Green EL. Protozoal causes of diarrhoea. PHLS Microbiology Digest, 1988;5:31-7.

7 Connolly GM, Dryden MS, Shanson DC, Gazzard BG. Cryptosporidial diarrhoea in AIDS and its treatment. Gut 1988;29:593-7

8 Casemore DP. Human cryptosporidiosis. In: Reeves DS Geddes AM, eds. Recent advances in infection. Vol 3. Edinburgh: Churchill Livingstone, 1989:209-36.

9 Cook GC. Small-intestinal coccidiosis: an emergent clinical problem. J Infect 1988;16:213-19.

10 Casemore DP. Epidemiological aspects of human Cryptosporidiosis. Epidemiol Infect 1990;104:1-28.

11 Colebunders R, Lusakumuni K, Nelson AM, et al. Persistent diarrhoea in Zairian AIDS patients: an endoscopic tent diarrhoea in Zairian AIDS patients: an

12 Hojlyng N, Jensen BN. Resp -atory cryptosporidiosis in HIV positive patients. Lancet $988 ; \mathrm{i}: 590-1$.

13 Kahn DG, Garfinkle JM, Kl off DC, Pembrook LJ Morrow DJ. Cryptosporid and cytomegaloviral hepatitis and cholecystitis. Arcn Pathol Lab Med 1987; 111:879-81.

14 Casemore DP, Armstrong M, Sands RL. Laboratory diag nosis of cryptosporidiosis. J Clin Pathol 1985;38:1337-41.

15 Loose JH, Sedegran DJ, Cooper HS. Identification of Cryptosporidium in paraffin-embedded tissue sections with the use of a monoclonal antibody. Am J Clin Pathol 1989;91:206-9.

16 Conlon PC, Pinching AJ, Perera CU, Moody A, Luo N, Lucas SB. HIV-related enteropathy in Zambia: a clinical, microbiological and histological study. Am J Trop Med Hyg 1990;42:83-8.

17 Soave R, Danner RL, Honig CL, et al. Cryptosporidiosis in homosexual men. Ann Intern Med 1984;100:504-11.

18 De Hovitz JA, Pape JW, Boncy M, Johnson WD. Clinica manifestations and therapy of Isospora belli infection in patients with the acquired immunodeficiency syndrome. $N$ Engl J Med 1986;315:87-90.

19 Sorvillo F, Lieb L, Iwakoshi K, Waterman SH. Isospora belli and the acquired immunodeficiency syndrome. $N$ Engl J Med 1990;322:131.

20 Sewankambo N, Mugerwa RD, Goodgame R, Carswell JW, Moody A, Lloyd G, Lucas SB. Enteropathic AIDS in Uganda: an endoscopic, histological and microbiological 
study. AIDS 1987;1:9-13.

21 Restrepo C, Macher AN, Radany EH. Disseminated extraintestinal isosporiasis in a patient with acquired immune deficiency syndrome. Am J Clin Pathol 1987; 87:536-42.

22 Pape JW, Verdier R-I, Johnson WD. Treatment and prophylaxis of Isospora belli infection in patients with the acquired immunodeficiency syndrome. $N$ Engl J Med 1989;320:1044-7.

23 Hart A, Ridinger MT, Soundarajan R, Peters CS, Swiatlo AL, Kocka FE. Novel organism associated with chronic diarrhoea in AIDS. Lancet 1990;i:169-70.

24 Canning EU, Lom J. The microsporidia of vertebrates. London: Academic Press, 1986

25 Desportes I, Le Charpentier Y, Galian A, et al. Occurrence of a new Microsporidian: Enterocytozoon bieneusi n.g., n.sp. in the enterocytes of

poridiosis and AIDS. Rev Infect Dis 1989;11:203-7.

27 Lucas S, Papadaki L, Conlon C, Sewankambo N, Goodgame $\mathrm{R}$, Serwadda D. Diagnosis of intestinal microsporidiosis $\mathrm{R}$, Serwadda D. Diagnosis of intestinal microsporid
in patients with AIDS. J Clin Pathol 1989;42:885-7.

28 Curry A, McWilliam LJ, Haboubi NY, Mandal BK. Microsporidiosis in a British patient with AIDS. $J$ Clin Pathol 1988;41:477-8.

29 Rijpstra AC, Canning EU, Van Ketel RJ, Eeftinck Schattenkerk JKM, Laarman JJ. Use of light microscopy to diagnose small-intestinal microsporidiosis in patients with AIDS. $J$ Infect Dis 1988;157:827-31.

30 Zender HO, Arrigoni E, Eckert J, Kapanci Y. A case of Encephalitozoon cuniculi peritonitis in a patient with Encephalitozoon cuniculi peritonitis in

31 Terada S, Reddy KR, Jeffers LJ, Cali A, Schiff ER. Microsporidian hepatitis in the acquired immunodeficiency syndrome. Ann Intern Med 1987;107:61-2.

32 Freidberg DN, Stenson SM, Orenstein JM, Tierno PM. Microsporidial keratoconjunctivitis in AIDS. Arch Ophthalmol 1990;108:504-8.

33 Microsporidian keratoconjunctivitis in patients with AIDS. Mortal Morbid Week Rep 1990;39:188-9.

34 Gerberding JL. Diagnosis and management of HIVinfected patients with diarrhoea. J Antimicrob Chemother 1989;23 (Suppl A):83-7.

35 Smith PD, Lane HC, Gill VJ, et al. Intestinal infections in patients with AIDS. Etiology and response to therapy. Ann Intern Med 1988;108:328-33.

36 Allason-Jones E, Mindel A, Sargeaunt P, Katz D. Outcome of untreated infection with Entamoeba histolytica in homosexual men with and without HIV antibody. Br Med $J$ 1988;297:654-6.

37 Lucas S. Missing infections in AIDS. Trans R Soc Trop Med Hyg 1990;84(Suppl 1):34-8.

$38 \mathrm{Zierdt} \mathrm{CH}$, Tan $\mathrm{HK}$. Ultrastructure and light microscope appearance of Blastocystis hominis in a patient with enteric disease. $Z$ Parasitenk 1976;50:277-83.

39 Rolston KVI, Winans R, Rodriguez S. Blastocystis hominis: pathogen or not? Rev Infect Dis 1990;11:61-2.

40 Garavelli PL, Orsi P, Scaglione L. Blastocystis hominis infection during AIDS. Lancet 1988 ;ii: 1364 .

41 McCabe R, Remington JS. Toxoplasmosis: the time has come. N Engl J Med 1988;318:313-5.

42 Anders KH, Guerra WF, Tomiyasu U, Verity MA, Vinters HV. The Neuropathology of AIDS. Am J Pathol 1986; 124:537-58.

43 Catterall JR, Hofflin JM, Remington JS. Pulmonary toxoplasmosis. Am Rev Respir Dis 1986;133:704-5.

44 Israelski DM, Skowron G, Leventhal JP, et al. Toxoplasma peritonitis in a patient with AIDS. Ann Intern Med 1988;148:1655-7.

45 Holliman RE. Toxoplasmosis and the acquired immune deficiency syndrome. J Infect 1988;16:121-8.

46 Tuazon CU. Toxoplasmosis in AIDS patients. $J$ Antimicrob Chemother 1989;23(Suppl A):77-82.

47 Benezra D, Brown AE, Polsky B, Gold JWM, Armstrong D. Babesiosis and Infection with Human Immunodeficiency virus (HIV). Ann Intern Med 1987;107:944.

48 Ong KR, Stavropoulos C, Inada Y. Babesiosis, asplenia and AIDS. Lancet 1990;336:112.

49 Nguyen-Dinh P, Greenberg AE, Mann JM, et al. Absence of association between Plasmodium falciparum malaria and $\mathrm{HIV}$ infection in children in Kinshasa, Zaire. Bull WHO 1987;65:607-13.

50 Simooya OO, Mwendapole RM, Siziya S, Fleming AF. Relation between falciparum malaria and HIV seropositivity in Ndola, Zambia. Br Med J 1988;297:30-1.

51 Wiley CA, Safrin RE, Davis CE, Lampert PW, Braude AI, phalitis in a patient with AIDS. J Infect Dis 1987;155: phalitis

52 Gonzalez MM, Gould E, Dickinson G, et al. AIDS associated with Acanthamoeba infection and other opportunistic organisms. Arch Pathol Lab Med 1986;110: 749-51.

53 Scaglia M, Villa $M$, Gatti S, Fabio F. Cutaneous leishmaniasis in AIDS. Trans $R$ Soc Trop Med Hyg 1989;83:338-9.
54 Gradoni L, Gramiccia M, Betti F. Fatal visceral disease caused by a dermotrophic Leishmania in a patient with human immunodeficiency virus infection. $J$ Infect 1990;20:180-2

55 Cook GC. 'Exotic' parasitic infections: Recent progress in diagnosis and management. J Infect 1990;20:95-102.

56 Smith D, Gazzard B, Lindley RP, et al. Visceral leishmaniasis (kala azar) in a patient with acquired immunodeficiency syndrome. AIDS 1989;3:41-3.

57 Rosenthal PJ, Chaisson RE, Hadley WK, Leech JH. Rectal leishmaniasis in a patient with acquired immunodeficiency syndrome. Am J Med 1988;84:307-9.

58 Greder A, Malet M, Gautier P, et al. Pleuresie revelatrice d'une leishmaniose au cours d'un syndrome d'immunodeficience acquise. Presse Medicale 1989;18:1390-1.

59 Alvar J, Blazquez J, Najera R. Association of visceral leishmaniasis and human immunodeficiency virus infections. J Infect Dis 1989;160:560-1.

60 Dellamonica P, Bernard E, Le Fichoux Y, et al. Allopurinol for treatment of visceral leishmaniasis in patients with AIDS. J Infect Dis 1989;160:904-

61 Morrow RH, Colebunders RL, Chin J. Interactions of HIV infection with endemic tropical diseases. AIDS 1989; 3(Suppl 1):S79-S87.

62 Stringer SL, Hudson K, Blase MA, Walzer PD, Cushion $M T$, Stringer JR. Sequence from ribosomal RNA of Pneumocystis carinii compared to those of four fungi suggests an Ascomycetous affinity. J Protozool 1989; 36:14-18S.

63 Mackenzie DWR. Pneumocystis carinii: A nomadic taxon. In: Mycoses in AIDS patients. New York: Plenum Press, 1990:55-63.

64 Hasleton PS, Curry A, Rankin EM. Pneumocystis carinii pneumonia: light microscopical and ultrastructural study. $J$ Clin Pathol 1981;34:1138-46.

65 Pifer LL, Hughes WT, Stagno S, Woods D. Pneumocystis carinii infection: evidence for high prevalence in normal and immunosuppressed children. Pediatrics 1978;61: $35-41$

66 Kovacs JA, Masur H. Prophylaxis of Pneumocystis carinii pneumonia: an update. J Infect Dis 1989;160:882-6.

67 Kovacs JA, Masur H. Pneumocystis carinii pneumonia: therapy and prophylaxis. J Infect Dis 1988;158:254-9.

68 Grimes MM, LaPook JD, Bar MH, et al. Disseminated Pneumocystis carinii infection in a patient with acquired immunodeficiency syndrome. Hum Pathol 1987;18:307-8.

69 Macher AM, Bardenstein DS, Zimmerman LE, et al. Pneumocystis carinii choroiditis in a male homosexual with AIDS and disseminated pulmonary and extrapulmonary P. carinii infection. N Engl J Med 1987;316:1092.

70 Smith MA, Hirschfield LS, Zahtz G, et al. Pneumocystis carinii otitis media. Am J Med 1988;85:745-6.

71 Schinella RA, Breda SD, Hammerschlag PE. Otic infection due to Pneumocystis carinii in an apparently healthy man with antibody to the human immunodeficiency virus. $A n n$ Intern Med 1987;106:399-400.

72 Carter TR, Cooper PH, Petri WA, et al. Pneumocystis carinii infection of the small intestine in a patient with AIDS. Am J Clin Pathol 1988;89:679-83.

73 Coulman CU, Green I, Archibald RWR. Cutaneous pneumocystosis. Ann Intern Med 1987;106:396-8.

74 Davey RT, Margolis D, Kleiner D, Deyton L, Travis W Digital necrosis and disseminated Pneumocystis carinii infection after aerosolized pentamidine prophylaxis. $A n n$ Intern Med 1990;111:681-2.

75 Awen CF, Baltzan MA. Systemic dissemination of Pneumocystis carinii pneumonia. Can Med Assoc J 1989; 104:809-12.

76 Sneed SR, Blodi CF, Berger BB, Speights JW, Folk JC. Pneumocystis carinii choroiditis in patients receiving inhaled pentamidine. N Engl J Med 1990;322:936-7.

77 Heyman MR, Rasmussen P. Pneumocystis carinii involvement of the bone marrow in acquired immunodeficiency syndrome. Am J Clin Pathol 1987;87:780-3.

78 Unger PA, Rosenblum M, Krown SE. Disseminated Pneumocystis in patient with AIDS. Hum Pathol 1988; 19:113-6.

79 Raviglione MC, Mariuz P, Sugar J, Mullen MP. Extrapulmonary Pneumocystis infection. Ann Intern Med 1989;111:339.

80 Saldana MJ, Mones JM. Cavitation and other atypical manifestations of Pneumocystis carinii pneumonia. Semin Diagnost Pathol 1989;6:273-86.

81 Masur H, Lane HC, Kovacs JA, Allegra CJ, Edman JC. Pneumocystis pneumonia: from bench to clinic. Ann Intern Med 1989;111:813-26.

82 Elvin KM, Bjorkman A, Linder E, Heurlin N, Hjerpe A. Pneumocystis carinii pneumonia: detection of parasites in sputum and bronchoalveolar lavage fluid by monoclonal antibodies. Br Med J 1988;297:381-4.

$83 \mathrm{Koch} M$, Heizmann W. Problems in the detection of Pneumocystis carinii by indirect immunofluorescence. Eur J Clin Microbiol Infect Dis 1990;1:58-9.

84 Thomas S, O'Doherty M, Bateman N. Pneumocystis carinii pneumonia. Aerosolised pentamidine gives effective prophylaxis. Br Med J 1990;300:211-12. 